\title{
Performance Assessment of Colorimetric Devices on Dental Porcelains
}

\author{
R.R. SEGHI, W.M. JOHNSTON ${ }^{1}$, and W.J. O'BRIEN ${ }^{2}$
}

University of California-Los Angeles, School of Dentistry, 10833 Le Conte Avenue, Los Angeles, California 90024; ${ }^{1}$ The Ohio State University, College of Dentistry, Columbus, Ohio 43210; and 'University of Michigan, School of Dentistry, Ann Arbor, Michigan 48109

The selection of an appropriate material that duplicates the appear. ance of natural tooth structure is very important in restorative dentistry. Photometric and colorimetric analysis techniques offer great potential as a tool for aiding in the duplication process. The degree to which these techniques will be useful depends on the accuracy and precision with which they can be applied to translucent as well as opaque surfaces. The purpose of this investigation was to evaluate the performance of three currently-available photometric devices.

The performance capabilities of the instruments were tested on various shades of opaque and translucent dental porcelain surfaces. The performance tests were designed for evaluation of the accuracy and precision of the instrument relative to a well-studied reference instrument. CIELAB color difference metrics were used for the performance analysis.

The results revealed that each of the photometric instruments evaluated was capable of producing color measurements with precision. However, the degree of accuracy with which the color measurements were made varied depending on the instrument used and the type of material surface being measured. A photo-electric tristimulus colorimeter showed the best overall performance on the porcelain surfaces, supporting its use as a valuable tool for evaluating color in dentistry.

J Dent Res 68(12):1755-1759, December, 1989

\section{Introduction.}

The ultimate goal of restorative dentistry is to restore missing tooth structure to natural form, function, and appearance. Duplicating the appearance of tooth structure is a complex process that requires careful control of the form, surface texture, translucency, and color of the restoration. A significant variation in any one of these factors will alter the overall appearance of the restoration and result in patient dissatisfaction. While each of these factors may be considered of equal importance to the overall appearance of a restoration, it appears that errors associated with color account for a significant portion of the variability that occurs in the duplication process.

Although the problems associated with the color-control process currently used have been well-discussed in the dental literature (Clark, 1931a,b,c; Sproull, 1973, 1974; Sorensen and Torres, 1987a), the process has remained relatively unchanged for over 50 years. The shade-control process most often used relies on a series of visual assessments that are communicated between two or more persons using shade guides and materials that have little standardization. The numerous problems associated with this process lead to varied and sometimes unpredictable results. Excellent techniques for improving the success of this process have been suggested, and some have led to impressive individual results (Kuwata, 1980; Muia, 1982; Sorensen and Torres, 1987a,b). This work has aided our understanding of the nature of the color appearance of natural teeth and the problems associated with their duplication. The proposed techniques, however, are somewhat labor-intensive and difficult for the average dentist to implement.

Received for publication December 14, 1988

Accepted for publication July 25, 1989

This work was supported by UCLA Academic Senate Grant 4090 and USPHS Research Grant DE-05423.
Rapid advances in optical electronic devices have led to the expanded use of photometric and colorimetric techniques for the evaluation, specification, and management of object color in many industrial situations. Instrumental colorimetric techniques allow for a rapid, consistent, quantitative assessment of material color and have been shown to be significantly more reliable in some situations than corresponding visual tasks (Jaekel and Ward, 1976; McLaren, 1976; Jeltsch and Fink, 1976). Although the effectiveness of utilizing these techniques in dentistry is still unclear, it will depend ultimately on the accuracy and precision with which the measurements can be carried out on translucent dental structures. Bangston and Goodkind (1982) have evaluated the performance of one tristimulus colorimeter on dental porcelain samples. Although a direct correlation was found to exist between the numerical data obtained on the test instrument and those obtained on a research-grade spectrophotometer, the visual significance of the results was difficult to assess.

This study was designed to evaluate the performance of three colorimetric devices when used to measure the color of opaque and translucent dental porcelain materials. The intentions were to determine the current limitations of these techniques and to establish some guidelines by which future work in this area should be carried out.

\section{Materials and methods.}

Sample preparation. - The method of sample preparation was designed so that any measurement errors which might be associated with sample geometry would be minimized. The specimens in this study were fabricated from commercially available dental porcelains (Vita VMK 68, Vita Zahnfabrik, Sackingen, West Germany). It was assumed that the porcelain disks were color-stable and could be used for subsequent instrumental colorimetric evaluations. Twelve opaque and body (translucent) porcelain powders were selected for evaluation. Table 1 summarizes the shades, codes, and batch numbers of porcelain powders used. Porcelain disks were prepared by a method similar to that described in more detail in a previous study (Seghi et al., 1986). Briefly, disks approximately 12 $\mathrm{mm}$ in diameter were fabricated with the various porcelain powders, by means of a press mold technique. The samples were ground flat on one side, then sectioned on a slow-speed diamond saw so that an approximately uniform thickness could be achieved. The opaque porcelain disks were sectioned to a $3-\mathrm{mm}$ thickness for total opacity and sample durability. The translucent samples were sectioned to a 1-mm thickness for simulation of the thickness that would be utilized in an ideal clinical situation. Final surface finish was achieved with use of standard petrographic polishing techniques with a series of graded abrasives. A $1-\mu \mathrm{m}$ diamond polishing paste was used for the final finish, which produced an approximately-uniform surface on all samples. The sectioning and polishing procedures resulted in samples whose mean thickness did not vary by more than $\pm 15 \mu \mathrm{m}$.

Spectrophotometric reference data. - Because color perception itself is based on psycho-physiological responses to light 
TABLE 1

SUMMARY OF PORCELAIN MATERIALS USED

\begin{tabular}{|c|c|c|c|c|c|c|c|c|c|c|c|c|c|}
\hline $\begin{array}{l}\text { Lumin Vacuum } \\
\text { Shade Designation }\end{array}$ & & $\mathrm{A} 1$ & A2 & A3 & A3.5 & A4 & B1 & B2 & $\mathrm{C} 1$ & $\mathrm{C} 2$ & $\mathrm{C} 4$ & $\mathrm{D} 2$ & D4 \\
\hline \multicolumn{14}{|l|}{ Opaque } \\
\hline Porcelains & Powder\# & 510 & 511 & 512 & 513 & 514 & 515 & 516 & 517 & 518 & 519 & 520 & 521 \\
\hline $\begin{array}{l}\text { (non-fluorescent) } \\
\text { Translucent }\end{array}$ & Batch\# & 693 & 652 & 408 & 306 & 78 & 502 & 314 & 76 & 466 & 389 & 689 & 241 \\
\hline Porcelains & Powder\# & 540 & 541 & 542 & 554 & 543 & 553 & 544 & 547 & 548 & 550 & 551 & 545 \\
\hline (fluorescent) & Batch\# & 797 & 672 & 601 & 447 & 134 & 594 & 162 & 799 & 479 & 544 & 829 & 488 \\
\hline
\end{tabular}

stimuli and may vary from one individual to another, the measurement of color in absolute terms is not possible. Therefore, it is convenient that the degree of conformance to results from a widely-used reference instrument be taken as a working definition of accuracy (Billmeyer, 1969). Reference reflectance data were obtained for each porcelain disk on a General Electric Hardy-type Recording Spectrophotometer with an integrating sphere (Hemmendinger Color Laboratory, 438 Wendover Drive, Princeton, NJ 08540). The performance of this instrument has been well-studied and long considered a reference instrument in the field (Billmeyer, 1965; Rhodes and Billmeyer, 1969). The spectrophotometer was calibrated with a white working standard traceable to absolute reflectance, as determined at the National Institute of Standards and Technology. We reduced the beam size to approximately $2 \mathrm{~mm}$ to minimize the effects of edge-loss errors (Atkins and Billmeyer, 1966; Hsia, 1976; Weidner, 1983). The translucent disks were backed by and optically connected to a corresponding opaque disk so that laboratory layering techniques routinely utilized in actual crown fabrication could be simulated. The optical connection between the disks was achieved with fluid of 1.5 index of refraction (R. P. Cargille Labs, Inc., 55 Commerce Rd., Cedar Grove, NJ 07009). We used absolute methods for reflection measurement techniques (CIE, 1979) to obtain the spectral data for each of the opaque and translucent porcelain sample disks at $10-\mathrm{nm}$ wavelength intervals. Specular component of reflectance was excluded for all measurements.

Test instrument selection and measurement procedures. While it is still unclear which configuration is most appropriate for color measurements, it has been generally felt that the diffuse $/ 0^{\circ}$ or, conversely, the $0^{\circ}$ diffuse type configurations are less sensitive to surface variations (Hardy, 1945) and have been recommended as the configuration of choice when translucent dental materials and structures are measured (Clarke, 1983). Only instruments that approximated one of these configurations were chosen for this study. The measurement of translucent materials presents some unique problems to photometric measurement procedures that require careful consideration in instrument selection. To minimize the effects of edge losses on photometric measurements, Weidner (1983) recommended that for the $0 \%$ diff. type configuration, the beam size be no greater than $50 \%$ of the illuminated port size. Alternatively, if the diff. $/ 0^{\circ}$ configuration is involved, the area of view or detection must be no more than $50 \%$ of the illuminated port size. Each of the instruments selected was able to accommodate the relatively small size of the samples to be measured $(<12 \mathrm{~mm}$ diam.) and maintain the appropriate minimum ratios mentioned above.

Two reflectance-type spectrophotometers and one photoelectric tristimulus colorimeter were chosen for evaluation. (A summary of the pertinent instrument information is given in Table 2.) Each one was calibrated according to the manufacturers' instructions, with use of their own calibration tiles. (All instruments were believed to be in proper working order.) Each sample disk was measured by each measuring device three times. The samples were measured in an arbitrary order. The three sample measurement sets were taken within about a twohour period. The spectrophotometric data were recorded as absolute reflectance or radiance factors. The colorimeter recorded the data directly in CIELAB coordinates relative to standard illuminant D65 and the 1931 standard observer functions (CIE, 1986). All data were transferred to a personal computer for manipulation and analysis.

Data manipulation and instrument performance evaluation procedures. - The numerical analysis techniques utilized in this investigation for assessment of the performance of the colormeasuring instruments were based on several previous investigations of this type (Robertson, 1967; Billmeyer, 1965; Billmeyer et al., 1974; Billmeyer and Alessi, 1981). The expression of various errors associated with instrumentation in terms of color difference metrics has been established as an effective means of providing performance information that is visually meaningful and was utilized in this investigation. All spectrophotometric data were mathematically converted to the CIE$\mathrm{LAB}$ coordinates relative to standard illuminant D65 and the 1931 standard observer functions, by means of standard colorimetric procedures (CIE, 1986). The errors associated with the sample measurements made by the different instruments were described in color-difference $(\Delta E)$ units. One $\Delta E$ unit is approximately equivalent to a visually just perceptible difference (Kuehni and Marcus, 1979).

Instrument accuracy was assessed by comparison of the measurements obtained with the test instrument $(t)$ with corresponding values obtained on the reference instrument $(R)$, which were accepted as being correct. The sizes of errors associated with the instruments' ability to obtain the color specification of individual opaque and translucent dental porcelain samples in absolute colorimetric terms $\left(\Delta \mathrm{E}_{\mathrm{Abs}}\right)$ were evaluated by the numerical method represented by Eq. 1:

(1) $\Delta \mathrm{E}_{\mathrm{Abs}}=\left(\left(\mathrm{L}_{\mathrm{R}}^{*}-\overline{\mathrm{L}^{*}}\right)^{2}+\right.$

$$
\left(a^{*}{ }_{R}-\overline{a^{*}}{ }^{2}\right)^{2}+\left(b^{*}{ }_{R}-\overline{b^{*}}{ }^{2}\right)^{1 / 2}
$$

where $L^{*}{ }_{R}, a^{*}{ }_{R}$, and $b^{*}{ }_{R}$ represent the measured $L A B$ values obtained on the reference instrument, and $\bar{L}^{*}, \bar{a}^{*}$, and $\bar{b}^{*}$, represent the mean values obtained from the three measurements made with the test instrument.

The relative accuracy of the test instruments or the accuracy of the color difference measurements was assessed in a manner analogous to that used for the absolute accuracy. Color difference values were calculated for each possible paired combination of the 12 samples within each porcelain group. The errors associated with the measurement of color differences between two samples $\left(\Delta \mathrm{E}_{\mathrm{Rel}}\right)$ were assessed by the numerical method represented by $\mathrm{Eq} .2$ :

$$
\text { (2) } \Delta \mathrm{E}_{\mathrm{Rel}}=\left|\Delta \mathrm{E}_{\mathrm{R}}-\overline{\Delta \mathrm{E}_{\mathrm{l}}}\right|
$$

where $\Delta E_{R}$ is the calculated color difference determined from the reference data, and $\Delta \mathrm{E}_{\mathrm{t}}$ is the mean of the corresponding differences obtained from the test-instrument measurements. 
TABLE 2

SUMMARY OF INSTRUMENT INFORMATION

\begin{tabular}{|c|c|c|c|c|}
\hline $\begin{array}{l}\text { Inst. } \\
\text { ID }\end{array}$ & Instrument Type & Instrument Name & Manufacturer & $\begin{array}{c}\text { Illum. \& View. } \\
\text { Geometry }\end{array}$ \\
\hline $\mathrm{R}$ & spectrophotometer & Hardy & $\begin{array}{l}\text { General Electric } \\
\text { (no longer produced) }\end{array}$ & $\begin{array}{l}0^{\circ} / \text { diff. } \\
\text { (monochromated illum.) }\end{array}$ \\
\hline S1 & $\begin{array}{l}\text { spectrophotometer } \\
\text { (Hardy-type) }\end{array}$ & Match-Scan & $\begin{array}{l}\text { Diano (Milton Roy) } \\
\text { Rochester, NY } 14625\end{array}$ & $\begin{array}{l}0^{\circ} / \text { diff. } \\
\text { (monochromated illum.) }\end{array}$ \\
\hline S2 & spectrophotometer & Spectrogard & $\begin{array}{l}\text { Gardner/Neotec } \\
\text { Silver Spring, MD } 20910\end{array}$ & $\begin{array}{l}\text { diff. } / 0^{\circ} \\
\text { (monochromated detect.) }\end{array}$ \\
\hline $\mathrm{C}$ & colorimeter & CR100 Chroma Meter & $\begin{array}{l}\text { Minolta Corp. } \\
\text { Ramsey, NJ } 07446\end{array}$ & $\begin{array}{l}\text { diff. } / 0^{\circ} \\
\text { (UV filtered illum.) } \\
\text { (filtered detectors) }\end{array}$ \\
\hline
\end{tabular}

In both cases, low $\Delta E$ values correspond to instruments with high accuracy.

The precision of a color-measuring instrument is related in part to its repeatability. Only the short-term $(<3 \mathrm{~h})$ repeatability was evaluated in this study. The errors associated with the repeatability of the $L^{*} a^{*} b^{*}$ measurements $\left(\Delta E_{L A B}\right)$ for each instrument were assessed by the numerical method represented by Eq. 3:

(3) $\Delta \mathrm{E}_{\mathrm{LAB}}=\left(\left(\overline{\mathrm{L}^{*}}{ }_{\mathrm{i}}-\mathrm{L}_{\mathrm{i}}^{*}\right)^{2}+\right.$

$$
\left.\left(\bar{a}_{t}{ }_{t}-a^{*}{ }_{i}\right)^{2}+\left(\bar{b}_{t}^{*}-b^{*}{ }_{i}\right)^{2}\right)^{1 / 2}
$$

where $L^{*}, \bar{a}^{*}$, and $\bar{b}^{*}$ represent the mean CIELAB values obtained from the three measurements made with the test instrument on a given sample, and $L^{*}{ }_{i}, a^{*}{ }_{i}$, and $b^{*}{ }_{i}$ represent the corresponding values produced from an individual measurement of that sample.

The errors associated with the repeatability of the color difference measurements $\left(\Delta E_{\mathrm{CD}}\right)$ for a given test instrument were assessed by the numerical method represented by Eq. 4:

$$
\text { (4) } \Delta E_{\mathrm{CD}}=\mid \overline{\Delta E_{\mathrm{t}}}-\Delta \mathrm{E}_{\mathrm{i}}
$$

where $\overline{\Delta E}_{\mathrm{t}}$ is the mean color difference between two samples, as determined from the three measurement sets generated by a test instrument, and $\Delta E_{i}$ represents the calculated color difference between the same two samples, as determined from an individual measurement set. In both cases, low $\Delta \mathrm{E}$ values relate to good repeatability.

The data from each of the performance tests were subjected to an analysis of variance, and the effects of the instrument and material types on the performance were examined. Tukey's multiple comparison procedure was performed on the data sets at a 0.05 level of significance. The results of the multiple comparisons tests are reported as the critical range (CR) for pairs of means. This value is the minimum difference between any pair required to reject the null hypothesis of no difference.

\section{Results.}

Table 3 gives a summary of the color difference values $(\Delta E)$ that were generated from Eq. 1 for assessment of the magnitude of errors associated with the specification of color in absolute terms. The mean and standard deviations of the calculated $\Delta E$ values for each instrument on the two material types are reported. The results of the two-way analysis of variance and the multiple comparisons test are shown adjacent to the descriptive statistics. The size of the errors that are likely to be associated with specification of color in absolute terms was significantly affected by both the type of instrument used $(p<0.001)$ and the nature of the material being measured $(\mathrm{p}<0.001)$. The significance of the interaction indicates that some instruments will perform better on translucent materials than others. In this examination, instrument $C$ showed the best performance with respect to absolute color measurements on both opaque and translucent materials, as evidenced by the statistically lower mean $\Delta \mathrm{E}$ values obtained. However, all instruments introduced errors that were of a magnitude great enough to be visually detected and which would have to be considered significant.

The results of the test designed for assessment of the relative accuracy or the accuracy of the color difference measurements (Eq. 2) are summarized in Table 4. The relative accuracy achieved was significantly affected $(p<0.01)$ by both the type of instrument used and the type of material being measured. Instrument $\mathrm{C}$ again showed the best overall performance, as evidenced by mean $\Delta E$ values significantly lower $(C R>0.19)$ than instruments $S 1$ or $S 2$. However, all mean $\Delta E$ values generated were well below the approximate perceptible limit of one $\Delta E$ unit.

The results of the short-term repeatability of the color-measuring devices with respect to measured $\mathrm{LAB}$ values and color difference values are summarized in Tables 5 and 6 , respectively. Each of the test instruments showed good repeatability, as evidenced by their low $\Delta E$ values. The approximate sizes of the errors associated with the repeatability of the measurements are similar in both situations and are well below the threshold of average human perception. It should be noted that although the descriptive statistics presented in Tables 5 and 6 are similar, the results of the corresponding inferential statistics

TABLE 3

ASSESSMENT OF THE ABSOLUTE ACCURACY OF INSTRUMENTAL COLORIMETRIC MEASUREMENTS ON

\begin{tabular}{|c|c|c|c|c|c|}
\hline \multicolumn{2}{|c|}{$\begin{array}{l}\text { Material Type: } \\
\text { Instrument }\end{array}$} & \multicolumn{2}{|c|}{$\begin{array}{c}\text { Opaque } \\
\Delta \mathrm{E}^{*} \pm \mathrm{sd}\end{array}$} & \multicolumn{2}{|c|}{$\begin{array}{c}\text { Translucent } \\
\Delta E^{*} \pm s d\end{array}$} \\
\hline $\begin{array}{l}\mathrm{S} 1 \\
\mathrm{~S} 2 \\
\mathrm{C}\end{array}$ & & \multicolumn{2}{|c|}{$\begin{array}{l}1.75 \pm 0.32 \\
2.75 \pm 0.48 \\
1.06 \pm 0.14\end{array}$} & \multicolumn{2}{|c|}{$\begin{array}{l}5.15 \pm 0.69 \\
5.16 \pm 0.53 \\
2.02 \pm 0.42\end{array}$} \\
\hline \multicolumn{6}{|c|}{$\begin{array}{l}\mathrm{n}=12 \text { for all groups. } \\
\text { Critical Range for pairs of means }=0.541 . \\
{ }^{*} \text { CIELAB, D65, } 2^{\circ} \text { observer. }\end{array}$} \\
\hline Source & $\begin{array}{l}\text { A } \\
\text { Sum of } \\
\text { Squares }\end{array}$ & $\begin{array}{l}\text { ALYSIS OF } \\
\text { Deg. of } \\
\text { Freedom }\end{array}$ & $\begin{array}{l}\text { ARIAN } \\
\text { Mean } \\
\text { Square }\end{array}$ & F-Ratio & Prob $>F$ \\
\hline $\begin{array}{l}\text { Between } \\
\text { Instrument } \\
\text { Between }\end{array}$ & 78.025 & 2 & 39.012 & 191.656 & 0.000 \\
\hline Material & 91.357 & 1 & 91.357 & 448.807 & 0.000 \\
\hline $\begin{array}{l}\text { Interaction } \\
\text { Error }\end{array}$ & $\begin{array}{l}17.956 \\
13.435\end{array}$ & $\begin{array}{r}2 \\
66\end{array}$ & $\begin{array}{l}8.978 \\
0.204\end{array}$ & 44.106 & 0.000 \\
\hline
\end{tabular}
DENTAL PORCELAIN (Eq. 1) 
TABLE 4

ASSESSMENT OF THE RELATIVE ACCURACY OF INSTRUMENTAL COLORIMETRIC MEASUREMENTS ON DENTAL PORCELAIN (Eq. 2)

\begin{tabular}{ccc}
\hline Material Type: & Opaque & Translucent \\
\hline Instrument & $\Delta \mathrm{E}^{*} \pm \mathrm{sd}$ & $\Delta \mathrm{E}^{*} \pm \mathrm{sd}$ \\
\hline S1 & $0.54 \pm 0.45$ & $0.75 \pm 0.54$ \\
S2 & $0.53 \pm 0.35$ & $0.64 \pm 0.40$ \\
C & $0.29 \pm 0.25$ & $0.25 \pm 0.21$ \\
\hline
\end{tabular}

$\mathrm{n}=66$ for all groups.

Critical Range for pairs of means $=0.190$.

${ }^{*}$ CIELAB, D65, $2^{\circ}$ observer.

\begin{tabular}{lrrrrr}
\multicolumn{7}{c}{$\begin{array}{c}\text { ANALYSIS OF VARIANCE } \\
\text { Source }\end{array}$} & $\begin{array}{c}\text { Sum of } \\
\text { Squares }\end{array}$ & $\begin{array}{c}\text { Deg. of } \\
\text { Freedom }\end{array}$ & $\begin{array}{c}\text { Mean } \\
\text { Square }\end{array}$ & F-Ratio & Prob $>$ F \\
\hline $\begin{array}{l}\text { Between } \\
\text { Instrument }\end{array}$ & 10.713 & 2 & 5.356 & 36.423 & 0.000 \\
$\begin{array}{l}\text { Between } \\
\text { Material }\end{array}$ & 0.859 & 1 & 0.859 & 5.844 & 0.016 \\
Interaction & 0.959 & 2 & 0.480 & 3.262 & 0.039 \\
Error & 57.352 & 390 & 0.147 & & \\
\hline
\end{tabular}

TABLE 5

SHORT-TERM REPEATABILITY OF LAB MEASUREMENTS (Eq. 3)

\begin{tabular}{ccc}
\hline \hline Material Type: & Opaque & Translucent \\
\hline Instrument & $\Delta \mathrm{E}^{*} \pm \mathrm{sd}$ & $\Delta \mathrm{E}^{*} \pm \mathrm{sd}$ \\
\hline S1 & $0.09 \pm 0.06$ & $0.13 \pm 0.06$ \\
S2 & $0.10 \pm 0.12$ & $0.12 \pm 0.10$ \\
C & $0.10 \pm 0.04$ & $0.09 \pm 0.04$ \\
\hline
\end{tabular}

$\mathrm{n}=12$ for all groups.

Critical Range for pairs of means $=0.092$.

*CIELAB, D65, $2^{\circ}$ observer.

\begin{tabular}{lccccc}
\multicolumn{1}{c}{$\begin{array}{c}\text { ANALYSIS OF VARIANCE } \\
\text { Source }\end{array}$} & $\begin{array}{c}\text { Sum of } \\
\text { Squares }\end{array}$ & $\begin{array}{c}\text { Deg. of } \\
\text { Freedom }\end{array}$ & $\begin{array}{c}\text { Mean } \\
\text { Square }\end{array}$ & F-Ratio & Prob > F \\
\hline $\begin{array}{l}\text { Between } \\
\text { Instrument }\end{array}$ & 0.003 & 2 & 0.002 & 0.291 & 0.749 \\
$\begin{array}{l}\text { Between } \\
\text { Material }\end{array}$ & 0.004 & 1 & 0.004 & 0.732 & 0.395 \\
Interaction & 0.007 & 2 & 0.003 & 0.580 & 0.563 \\
Error & 0.387 & 66 & 0.006 & & \\
\hline
\end{tabular}

TABLE 6

SHORT-TERM REPEATABILITY OF $\triangle E$ MEASUREMENTS (Eq. 4)

\begin{tabular}{ccc}
\hline \hline Material Type: & Opaque & Translucent \\
\hline Instrument & $\Delta \mathrm{E}^{*} \pm \mathrm{sd}$ & $\Delta \mathrm{E}^{*} \pm \mathrm{sd}$ \\
\hline S1 & $0.06 \pm 0.05$ & $0.09 \pm 0.07$ \\
S2 & $0.10 \pm 0.12$ & $0.14 \pm 0.11$ \\
$\mathrm{C}$ & $0.06 \pm 0.04$ & $0.05 \pm 0.03$ \\
\hline
\end{tabular}

$\mathrm{n}=66$ for all groups.

Critical Range for pairs of means $=0.039$.

${ }^{*}$ CIELAB, D65, $2^{\circ}$ observcr.

\begin{tabular}{lccccc}
\multicolumn{7}{c}{$\begin{array}{c}\text { ANALYSIS OF VARIANCE } \\
\text { Source }\end{array}$} & $\begin{array}{c}\text { Sum of } \\
\text { Squares }\end{array}$ & $\begin{array}{c}\text { Deg. of } \\
\text { Freedom }\end{array}$ & $\begin{array}{c}\text { Mean } \\
\text { Square }\end{array}$ & F-Ratio & Prob > F \\
\hline $\begin{array}{l}\text { Between } \\
\text { Instrument }\end{array}$ & 0.326 & 2 & 0.163 & 26.343 & 0.000 \\
$\begin{array}{l}\text { Between } \\
\text { Material }\end{array}$ & 0.043 & 1 & 0.043 & 7.026 & 0.008 \\
Interaction & 0.049 & 2 & 0.024 & 3.957 & 0.020 \\
Error & 2.412 & 390 & 0.006 & & \\
\hline
\end{tabular}

are quite different. The repeatability of the LAB measurements was not significantly affected $(p>0.05)$ by the instrument used or by the type of material being measured, while the repeatability of the color difference measurements was significantly affected $(p<0.01)$ by both factors. Differences in statistical results are related to differences in the size of the mean squared errors of the two populations and warrants some discussion.

\section{Discussion.}

Photometric analysis techniques of material surfaces, coupled with mathematical modeling systems (Kubelka and Munk, 1931; Johnston et al., 1986), offer the potential for improvement in our abilities to evaluate, design, and select the most appropriate aesthetic restorative materials. A description of the performance limitations of color-measuring devices in terms of the errors associated with the measurements made on dental materials is helpful in the assessment of their usefulness and provides information that may guide the development of future applications and clinical instrumentation.

Photometric measurements used for color evaluations are subject to a number of error sources. Both systematic and random errors can occur in the color-measurement process. Systematic errors include those resulting from factors such as inaccurate calibration techniques, wavelength, bandwidth, detector linearity, filter design, fluorescence, and variations in measuring geometries. Random errors can occur as a result of background noise, instrument drift, polarization, sample preparation, and presentation. Quantitatively, systematic errors tend to affect the accuracy of the instrument, and random errors tend to affect the precision of repeatability of the instrument (Berns and Petersen, 1988).

Random components of errors are more easily reduced with suitable statistical pooling of data, precise sample preparation, and careful sample presentation (Clarke, 1972), as was done in this experiment. Under such conditions, most modern color measuring instruments are capable of very high precision (Judd and Wyszecki, 1975; Billmeyer and Saltzman, 1981). Many if not the majority of colorimetric assessments in practice require only a device that is precise, and the accuracy is of little significance. This type of instrument is particularly important in the production of color-control situations. Its purpose in this case is merely to accept or reject an object as being the same in color.

Systematic errors are not as easily detected or managed as are the random components of errors. The accuracy of colormeasuring devices is therefore subject to greater variability. Absolute accuracy is most significantly affected by these types of errors, and large discrepancies can be expected to occur between instruments even under controlled conditions. Therefore, the practical use of measurements of this type is of little value, and the performance of the instrument in this regard is of least importance. Of much greater importance and of more practical use is the ability of an instrument to assess the color difference between objects accurately. The more consistent performance of the test instruments with respect to relative accuracy supports the use of differential colorimetry as the most effective method for colorimetric analyses. The use of differential measurements greatly reduces the effects of many systematic errors, and good color difference accuracy can be achieved in a variety of circumstances (Judd and Wyszecki, 1975; Billmeyer and Saltzman, 1981).

Research-grade spectrophotometers have been used traditionally when high-accuracy colorimetric data are desired. While these types of devices remain the instruments of choice in many analyses, our study indicates that their routine use to 
obtain colorimetric data does not guarantee a higher degree of accuracy. The exceptionally good performance, relatively small measuring port, and the easy use of the photo-electric tristimulus colorimeter evaluated in this study attest to its potential usefulness as a means of assessment of color differences between both opaque and translucent dental materials.

Regardless of the instrumental technique used for the evaluation of color, the final assessments are always visual ones. The most useful numerical assessments, then, are those that have some relationship to visual perception, and the CIELAB system is currently recommended for use in this regard. While conventional statistical analysis techniques can be readily applied to the numerical data, caution must be used in the interpretation of such results. As illustrated in Tables 5 and 6 , conclusions based solely on inferential statistical assessments can be quite misleading. In this case, one might conclude that the $L^{*} a^{*} b^{*}$ measurements are not significantly affected $(p>0.05)$ by the type of instrument used or by the type of material being measured, while the contrary is true for the precision of the color difference measurements. The sizes of the errors in both cases, however, are similar in magnitude and significantly less than the approximate visual threshold of perception. Since the final judgment in any colorimetric assessment is a visual one, it is necessary that we continue to establish more exact relationships between visual and instrumental analysis within the area of color space occupied by natural teeth.

\section{Acknowledgments.}

We would like to thank Mr. Henry Hemmendinger and Mr. Maxwell Saltzman, whose knowledge of color science we respect and admire, and whose stimulating conversations on several occasions have resulted in new ideas and a further understanding of this complex subject.

\section{REFERENCES}

ATKINS, J.T. and BILLMEYER, F.W., Jr. (1966): Edge-Loss Errors in Reflectance and Transmittance Measurement of Translucent Materials, Mater Res Stand 6:564-569.

BANGSTRON, L.K. and GOODKIND, R.J. (1982): The Conversion of Chromascan Designations to CIE Tristimulus Values, $J$ Prosthet Dent 48:610-617.

BERNS, R.S. and PETERSEN, K.H. (1988): Empirical Modeling of Systematic Spectrophotometric Errors, Color Res Appl 13:243256.

BILLMEYER, F.W. (1965): Precision of Color Measurement with the GE Spectrophotometer. I. Routine Industrial Performance, $J$ Opt Soc Am 55:707-717.

BILLMEYER, F.W., Jr. (1969): Comparative Performance of ColorMeasuring Instruments, Appl Optics 8:755-783.

BILIMMEYER, F.W., Jr. and ALESSI, P.J. (1981): Assessment of Color-Measuring Instruments, Color Res Appl 6:195-202.

BILLMEYER, F.W.; CAMPBELL, E.D.; and MARCUS, R.T. (1974): Comparative Performance of Color-Measuring Instruments; Second Report, Appl Optics 13:1510-1518.

BILLMEYER, F.W. and SALTZMAN, M. (1981): Principles of Color Technology, 2nd ed., New York: John Wiley \& Sons, pp. $67-110$.

CIE PUBLICATION No. 44 (TC-2.3) (1979): Absolute Methods for
Reflection Measurements, Paris: Bureau Central de la CIE, p. 29.

CIE PUBLICATION No. 15.2 (1986): Colorimetry, Vienna: Central Bureau of the CIE, p. 74

CLARK, E.B. (1931a): The Color Problem in Dentistry: Introduction, Dent Dig 37:499-509.

CLARK, E.B. (1931b): The Color Problem in Dentistry: A Practical Application of the Psychological Primary Colors, Dent Dig 37:571583.

CLARK, E.B. (1931c): The Color Problem in Dentistry: The Physical Nature of Color, Dent Dig 37:646-659.

CLARKE, F.J. (1972): High Accuracy Spectrophotometry at the National Physical Laboratory, J Res Natl Bur Stand 76A:375-403.

CLARKE, F.J. (1983): Measurement of Colour of Human Teeth in Dental Ceramics. In: Proceedings of the First International Symposium on Ceramics, J.W. McLean, Ed., Chicago: Quintessence Publ. Co., Inc., pp. 441-489.

HARDY, A.C. (1945): Illuminating and Viewing Conditions for Spectrophotometry and Colorimetry, $J$ Opt Soc Am 35:289-292.

HSIA, J.H. (1976): The Translucent Blurring Effect-Method of Evaluation and Estimation, NBS Technical Note 594-12, p. 25.

JAEKEL, S.M. and WARD, C.D. (1976): Practical Instrumental Color Quality Control-the Hatra Experience, $J$ Soc Dyers Colour 92:353363.

JELTSCH, K. and FINK, X. (1976): Analysis of Errors in Accept ability Experiments, $J$ Soc Dyers Colour 92:227-232.

JOHNSTON, W.M.; O'BRIEN, W.J.; and TIEN, T.Y. (1986): Concentration Additivity of Kubelka-Munk Optical Coefficients of Porcelain Mixtures, Color Res Appl 11:131-137.

JUDD, D.B. and WYSZECKI, G. (1975): Color in Business, Science and Industry, 3rd ed., New York: John Wiley and Sons, pp. 91-219.

KUBELKA, P. and MUNK, F. (1931): Ein Beitrag zur Optik der Farbanstriche, $Z$ Tech Phys 12:593-601.

KUEHNI, R.G. and MARCUS, R.T. (1979): An Experiment in Visual Scaling of Small Color Differences, Color Res Appl 4:83-91.

KUWATA, M. (1980): Theory and Practice for Ceramo Metal Restorations, Chicago: Quintessence Publ. Co., Inc., p. 43.

McLAREN, K. (1976): An Introduction to Instrument Shade Passing and Sorting and a Review of Recent Developments, $J$ Soc Dyers Colour 92:317-326

MUIA, P.J. (1982): The Four Dimensional Tooth Color System, Chicago: Quintessence Publ. Co., Inc., pp. 11-57, 105-157.

RHODES, E.C. and BILLMEYER, F.W., Jr. (1969): Precision of Color Measurement with the GE Spectrophotometer II: Photometric Accuracy, Appl Optics 8:769-773.

ROBERTSON, A.R. (1967): Colorimetric Significance of Spectrophotometric Errors, $J$ Opt Soc Am 57:691-698.

SEGHI, R.R.; JOHNSTON, W.M.; and O'BRIEN, W.J. (1986): Spectrophotometric Analysis of Color Differences Between Porcelain Systems, $J$ Prosthet Dent 56:35-40.

SORENSEN, J.A. and TORRES, T.J. (1987a): Improved Color Matching of Metal-Ceramic Restorations. Part I: A Systematic Method for Shade Determination, $J$ Prosthet Dent 58:133-139.

SORENSEN, J.A. and TORRES, T.J. (1987b): Improved Color Matching of Metal-Ceramic Restorations. Part II: Procedures for Visual Communication, J Prosthet Dent 58:669-677.

SPROULL, R.C. (1973): Color Matching in Dentistry, Part IY. Practical Applications for the Organization of Color, $J$ Prosthet Dent 29:556-566.

SPROULL, R.C. (1974): Color Matching in Dentistry, Part III. Color Control, $J$ Prosthet Dent 31:146-154.

WEIDNER, V.R. (1983): White Opal Glass Diffuse Spectral Reflectance Standards for the Visible Spectrum (SRM's 2015 and 2016), NBS Special Publication 260-82, p. 21. 